First Peoples Child \& Family Review

An Interdisciplinary Journal Honouring the Voices, Perspectives, and Knowledges of First Peoples through Research, Critical Analyses, Stories, Standpoints and Media Reviews

\title{
"Why Do I Need to Sign it? Issues in Carrying Out Child Assent in School-Based Prevention Research Within a First Nation Community
}

\author{
Lola Baydala, Sherry Letendre, Lia Ruttan, Stephanie Worrell, Fay Fletcher, Liz \\ Letendre and Tanja Schramm
}

Volume 6, Number 1, 2011

URI: https://id.erudit.org/iderudit/1068899ar

DOI: https://doi.org/10.7202/1068899ar

See table of contents

Publisher(s)

First Nations Child and Family Caring Society of Canada

ISSN

1708-489X (print)

2293-6610 (digital)

Explore this journal

Cite this article

Baydala, L., Letendre, S., Ruttan, L., Worrell, S., Fletcher, F., Letendre, L. \& Schramm, T. (2011). "Why Do I Need to Sign it? Issues in Carrying Out Child Assent in School-Based Prevention Research Within a First Nation Community. First Peoples Child \& Family Review, 6(1), 99-113.

https://doi.org/10.7202/1068899ar

\section{Article abstract}

The practice of and procedures for obtaining child assent in research involving children are based in Western conceptions of individual decision-making rights, free from any form of coercion including that of parents. In the context of obtaining assent for children involved in research in an Alberta First Nation, the issue can become more complex given respect for ethical frameworks based in collective decision-making and the responsibility of Elders and families to protect children in interactions with Western institutions. This article explores the results of a focus group held to discuss our experience with child assent in research taking place with a community-initiated and culturally-adapted substance abuse prevention program being taught in the community school. In this case the process of being asked to sign written individual assent in the classroom was perceived as bearing extrinsic risk. Given collective cultural norms, the communities past experiences with the safety of signatures, and the proper roles of Elders and family, the children asked "Why do I have to sign it" when asked to sign their assent for participation in the project. A process that involved gathering child assent with children surrounded by family and community was recommended. Greater researcher and REB responsiveness to the issue of non-malfeasance is needed, in this case, by not asking researchers and community members to act in ways that violate culturally-based ethical norms and protocol all of which are important to community continuity, self-determination, and well-being.
Copyright (c) Lola Baydala, Sherry Letendre, Lia Ruttan, Stephanie Worrell, Fay Fletcher, Liz Letendre, Tanja Schramm, 2011
This document is protected by copyright law. Use of the services of Érudit (including reproduction) is subject to its terms and conditions, which can be viewed online.

https://apropos.erudit.org/en/users/policy-on-use 


\title{
First Peoples Child \& Family Review
}

An Interdisciplinary Journal Honoring the Voices, Perspectives and Knowledges of First Peoples through Research, Critical Analyses, Stories, Standpoints and Media Reviews

\section{"Why Do I Need to Sign it? Issues in Carrying Out Child Assent in School-Based Prevention Research Within a First Nation Community}

\author{
Lola Baydalaa, Sherry Letendre ${ }^{\mathrm{b}}$, Lia Ruttan ${ }^{\mathrm{a}}$, Stephanie Worrella, Fay Fletcher ${ }^{\mathrm{c}}$, Liz \\ Letendre $^{\mathrm{b}}$, and Tanja Schramm ${ }^{\mathrm{b}}$
}

a Department of Pediatrics, University of Alberta;

${ }^{b}$ Alexis Nakota Sioux Nation School, Alberta; and

${ }^{\mathrm{c}}$ Faculty of Extension, University of Alberta.

\section{Introduction}

Research involving children requires the free and informed consent of parents or guardians along with the assent of the children involved. Informed consent is understood to involve the issues of competence to decide, the provision of adequate information, and confirmation of the voluntary nature of consent (Beauchamp \& Childress, 2001). Informed consent with children contains two parts: parental consent and child assent. Parental consent refers to parent's or guardian's informed consent to allow the researcher to ask the child if they agree to participate in research; their agreement is called child assent (Broome, 1999; Meaux \& Bell, 2001). In cases where consent is received from parents or guardians but the child does not give assent, or later changes their mind, the child's wishes are respected. Meaux and Bell (2001) suggest that the

Questions or correspondence concerning this article may be addressed to:

Lola Baydala

Children's Health Clinic

Misericordia Community Hospital

16930-87 Avenue, Edmonton, AB, T5R 4H5.

Email: lola.baydala@albertahealthservices.ca

\begin{abstract}
The practice of and procedures for obtaining child assent in research involving children are based in Western conceptions of individual decision-making rights, free from any form of coercion including that of parents. In the context of obtaining assent for children involved in research in an Alberta First Nation, the issue can become more complex given respect for ethical frameworks based in collective decision-making and the responsibility of Elders and families to protect children in interactions with Western institutions. This article explores the results of a focus group held to discuss our experience with child assent in research taking place with a community-initiated and culturally-adapted substance abuse prevention program being taught in the community school. In this case the process of being asked to sign written individual assent in the classroom was perceived as bearing extrinsic risk. Given collective cultural norms, the communities past experiences with the safety of signatures, and the proper roles of Elders and family, the children asked "Why do I have to sign it" when asked to sign their assent for participation in the project. A process that involved gathering child assent with children surrounded by family and community was recommended. Greater researcher and REB responsiveness to the issue of non-malfeasance is needed, in this case, by not asking researchers and community members to act in ways that violate culturally-based ethical norms and protocol all of which are important to community continuity, self-determination, and well-being.

Keywords: child assent; First Nations children; research ethics; community-based participatory research; Indigenous research; research ethics boards.
\end{abstract}

process of obtaining assent from children should involve providing information in developmentally appropriate language and obtaining assent in an environment separate from the direct influence of parents and institutional representatives, including health care providers and teachers. 


\section{Acknowledgements:}

The authors wish to acknowledge the work of community Elders who made significant contributions to adapting and delivering this program. This research was conducted as part of a larger project funded by the Canadian Institute of Health Research and the Alberta Centre for Child, Family and Community Research.

These definitions of consent and assent are derived from Western assumptions about the importance of autonomous decision making and the ethical procedures involved in protecting that autonomy. The ethical dilemmas created by attempts to meet criteria for consent driven by these assumptions and processes can lead to further ethical dilemmas in the context of research with First Nations peoples who live and act within an ethical framework based in collective decision making (Ball \& Janyst, 2008; Brant Castellano, 2004; Fletcher et al., 2010; Holkup et al., 2009). Given the likelihood that a First Nations community may take a collective approach to making ethical decisions, the ethics of research involving children, including obtaining parental or guardian consent and child assent takes on unique challenges in community-based research.

This article reviews the literature on free and informed child assent and discusses the contradictions and challenges of gathering child assent experienced during a community-based participatory research (CBPR) project carried out in partnership with the Alexis Nakota Sioux Nation located in Western Canada. This community. initiated research project involved the cultural adaptation of the Botvin Life Skills Training (LST) Program followed by implementation and evaluation. The LST program is an evidencebased substance abuse prevention program delivered in school settings developed by Gilbert Botvin (Botvin \& Griffin, 2004; Botvin, Griffin, Paul, \& Macaulay, 2003). Prior to delivery, the LST program was culturally adapted by a team of Nakota Sioux Elders, community resource people, and staff members from the community school. The adapted program, named Nimi Icinohabi, added cultural teachings, values, Stoney language, cultural activities, and local art and visual images to the core LST program. Nimi Icinohabi was delivered by trained community members and evaluated using both quantitative and qualitative methodologies (Baydala et al., 2009). Parental/ guardian consent and child assent were obtained for involvement in the program evaluation (Fletcher et al., 2010). Throughout the duration of the project, processes associated with obtaining adult consent and child assent were problematic. A focus group was held with research team members to document concerns and to explore possible solutions. Issues and strategies specific to parental/guardian consent are addressed in an earlier article (Fletcher et al., 2010). In this article we look specifically at perspectives regarding how, where, and whether child assent should be obtained based on the experience and views of the research team. This issue has not been addressed to any significant degree. We hope that this discussion will open up consideration of this issue for practitioners of CBPR in projects involving First Nations children.

\section{Issues in Research Consent Involving Children}

One of the early concerns for research ethics in 20th century North America involved the ethics of medical research practices with children, often orphans or other institutionalized children, as well as children from other marginalized groups (Burns, 2003; Lederer \& Grodin, 1994). These circumstances, along with the after-shocks of the Nazi medical research post-World War II, led to an increased emphasis on the development of basic research principles including those of autonomy (independence of decision-making), non-malfeasance (doing no harm), beneficence (benefit), and justice (equality of representation and of risks/benefits) (Beauchamp and Childress, 2001). Codes of ethical principles were also 
developed, including the Nuremberg code in 1949, Declaration of Helsinki by the World Medical Association in 1964, and the influential Belmont report in 1978 which followed the finding of highly unethical, race-based medical research practices at the Tuskegee Institute in the United States (Meaux \& Bell, 2001; Nelson-Marten \& Rich, 1999). Along with these emerging research principles and codes came much more stringent limits to research with children (Burns, 2003).

In Canada, guidelines for informed consent and assent in research involving children are contained in the Tri-Council Policy Statement Second Edition (TCPS-2) developed as part of the work of three national funding bodies in medicine, science, and the social sciences (Canadian Institutes of Health Research, Natural Sciences and Engineering Research Council of Canada, and Social Sciences and Humanities Research Council of Canada, 2010). This policy indicates that researchers must consider participants' capacity to provide consent for themselves (Article 3.9). In the case of minor children, this has meant that permission from the proper third party, parents or legal guardians, must be received. Authorization by parents or guardians is based on the assumption that they are most fit to protect the child's interests. Research involving children must balance vulnerability with any injustice occurring as a result of their omission from pertinent research; for example, over-reliance on adult-based research results or research that does not include minority groups (Canadian Institutes of Health Research; Natural Sciences and Engineering Research Council of Canada; Social Sciences and Humanities Research Council of Canada, 1998; Meaux \& Bell, 2001). This issue is further complicated by legal, developmental, and socio-cultural determinants of children's decision-making readiness and responsibility (Baylis, Downie, \& Kenny, 1998). Therefore, researchers must indicate in their REB applications how children's best interests will be protected, coercion avoided, and their involvement limited to no more than minimal risk without direct benefits (Canadian Institutes of Health Research et al., Article 2.5, 1998). Further, Baylis et al. (1998) recommend that what children want to know, what their understanding and decisionmaking capacity is, and what they need to know should all be considered in conducting child assent processes.

Current trends in regards to child assent include an increasing focus on their capacity and individual rights (Hill, 2005; Powell \& Smith, 2009; Weithorn \& Scherer, 1994). From this perspective, Powell and Smith (2009) hold that, "children should be viewed, not as vulnerable passive victims, but as social actors who can play a part in the decision to participate in research" (p. 638). The right of the child to express his or her views in all matters affecting them, given consideration for age and maturity, is enshrined in the United Nations Convention on the Rights of the Child (Morrow \& Richards, 1996). This emphasis on rights is seen by ethicists and institutional ethics review boards to be empowering, as "the opportunity to give or deny informed consent is not only a right in relation to research which children share with adults, but also contributes to their wellbeing, through giving respect to their sense of control" (Hill, 2005, p. 68). Interestingly, in a study involving children's understanding of these rights as research participants, Hurley and Underwood (2002) found that grade school children understood what they were asked to do and what their research rights were but generally did not understand the purpose of the study.

\section{Ethical Issues in School- Based Research}

In school settings, consent may involve many layers. For example, school boards or trustees may need to give permission for a research project to take place, approval by school principals is required, parents or guardians must give consent either actively or passively, and children need to give their assent. In the past, requests to parents for their children's participation in school-based research programs were simply sent home with a cover letter and no response was interpreted as indicating consent. Increasingly, active response or 
return of forms is required and failure to return the forms is assumed to represent lack of permission (Esbenson et al., 1996; Esbensen, Melde, Taylor, \& Petersen, 2008). Debate about best practices in regards to parental consent is an ongoing issue. Rates of return or failure to return forms often are not truly representative of parents' true awareness of or thoughts on project participation and may further marginalize some children whose perspectives are important and who may accrue direct benefit through participation (Esbenson et al., 1996; Esbensen et al., 2008).

Another issue involves obtaining the child's assent in the school setting where the roles and relative authority of adults and children are typically quite clear. Giving assent may be compounded by the expected compliance of children within the institution. Asking children whether or not they wish to participate in non-research related activities is unusual in educational contexts. Educational institutions are a setting of authority; the degree of autonomy for any child participant within that context raises concerns. Involvement of school personnel in dual roles within the research project, although not uncommon, is usually not recommended and is understood as presenting unique challenges in terms of obtaining assent, confidentiality, and autonomy (Hammack, 1997; Nolen \& Putten, 2007). Finally, the participation of First Nations children in research within the school context is a particularly sensitive issue given the devastating harm done to families and communities through colonizing educational institutions, including residential schools.

\section{Challenges to Obtaining Informed Assent with Children in First Nations and other Aboriginal Communities}

Children are not isolated research participants; they are embedded in the context of their family, community, and cultural backgrounds which all play a part in the process of parental consent and child assent (Baylis et al., 1998; Holaday, Gonzales, \& Mills, 2007). The context of cultural and historical background is particularly salient in the case of First Nations and other Aboriginal peoples. In speaking of international research settings, bioethicist Patricia Marshall (2006) states that in the conduct of research extrinsic vulnerability, or vulnerability related to outside factors, "occurs where certain population subgroups are denied social and political rights" ( $p$. 30). In Canada, the issue of extrinsic vulnerability is especially pertinent, given the history of harm to First Nations, Inuit, and Métis children and the denial of control or self-determination to their families. As a result, it is critical that the collective context be given priority and that ethics be rooted in the community, in relationship, and in respect for Indigenous research principles and collaborative practices; otherwise, we are destined to replay history, causing enduring harm to individuals and whole communities (Brant Castellano, 2004; Ruttan, 2004). The American Academy of Pediatrics (2004) acknowledges that, "there are communities in North America in which cultural perception and historical experience create a different, somewhat hostile view of Western science and research" (p. 148). Additionally, the "collective risks to members of specific geographic, racial, religious, or ethnic communities" (p. 148) caused by superficial attention to ethical conduct in research must be a thing of the past.

Ball and Janyst (2008) note that for many Indigenous communities, given the integration of "children's wellbeing in family and community health and wellness across generations, the family, or sometimes the community, is a more culturally fitting unit of analysis rather than the child alone" (p. 43). This raises the question of who should give consent. Panagiotopoulos, Rozmus, Gagnon, and Macnab (2007) indicate that great care for protocol, involving a three stage process with the entire community, was an important aspect of this community-initiated research project involving diabetes screening for children in a First Nations community located on the west coast of Canada. 
While full community, parent or guardian consent, and child assent was received, community members expressed reluctance for children to sign assent. They indicated that ideally Elders who are responsible for children's wellbeing would make this decision and, at the very least, parents should be able to sign for their children.

Addressing these same issues, Ball (2005) noted that researchers must be flexible and open to negotiating the process of obtaining research consent on a case by case basis, especially in "regards to protection of the rights of children and families and promotion of that particular community's well-being" (p. 4). She stressed that, given historical and cultural factors, obtaining consent and assent "should not require isolation of children from their caregivers. Parents should be fully informed of what will be done with their children and special steps should be taken to explain their right of refusal" (Ball, 2005, p. 4). Further, Fisher, Hoagwood, Boyce, et al., (2002) suggest that in work with minority groups, including Native Americans, "investigator's should make an effort to understand expectations about guardian permission and child assent that reflect cultural attitudes, values, and histories related to the roles of family members and community structures in decisions regarding the welfare of children and adolescents" (p. 130).

\section{Background to Research Approach and Consent Procedures}

From the start, principles of CBPR (Israel, Schultz, Parker, \& Becker, 1998) and guidelines from the TCPS (Canadian Institute of Health Research et al., 1998; Canadian Institutes of Health Research et al., 2010), as well as, the Canadian Institute of Health Research's document, Guidelines for Health Research Involving Aboriginal Research (2007) informed the research team's decisions regarding ethical conduct (Baydala et al., 2009; Baydala et al., 2010). Shore and colleagues note that CBPR, "challenges us to expand the traditional framework of ethical analysis to include community-level and partnership-oriented considerations" (Shore, Wong, Seifer, Grignon, \& Gamble, 2008, p. 1). In First Nations and other Aboriginal communities, issues of reliance on outside authority and expertise at the expense of self-determination and cultural relevance are now rejected (Brant Castellano, 2004; Schnarch, 2004; Smith, 1999). Research requires the active involvement and consent of both the community and individual participants. By using an appropriate approach to research and acting from an appropriate ethical basis we attempted to equalize research partnerships and processes (Castledon, Garvin, \& Huu-ay-aht First Nation, 2008).

Initial community consent for the CBPR LST project involved several steps including Elder's approval for the overall research project, along with oral consent for their own involvement in various aspects of the project, such as focus groups. A resolution of support from the Chief and Council in the form of a Band Council Resolution (BCR) was received and a community consultation meeting held. Community-based research team members advised us that parental consent would require respectful and informational visits to parent and/or guardian's homes by a communitybased researcher. Historically, signing papers with Western institutions have resulted in negative consequences for First Nations communities. Involving community insiders who were members of the research team would help address issues of trust, ensure use of proper protocol, and communicate community partnership (Ball \& Janyst, 2008).

The importance of children and youth to the community was emphasized by Elders, leaders, and community educators. Children are understood to live within family, clan, and community and are taught respect and responsibility along with the importance of kinship and relationship. The Alexis Nakota Sioux kinship and clan system means that the whole community is responsible for raising the child. Adults endeavor to protect children from situations that ask them to act contrarily to 
community values. Parents and guardians, usually grandparents or other relatives, are considered the decision-makers for children especially in contexts involving Western institutions. Elders are essential in teaching cultural values, protocol, and behavior to children. The right to protect and the responsibility to teach their children has historically been denied to many First Nations families through the phenomenon of residential schooling and the practice of placing children in the custody of non-First Nations foster and adoptive families.

\section{The Focus Group}

During the course of this research project numerous issues arose in terms of consent and assent processes requiring frequent discussion at monthly team meetings and requests for amendments to the University-based REB. An initial focus group was designed to discuss the issues that arose during the process of gaining consent. After identifying child assent as an issue in the initial session, members of the research group gathered to further explore the process and ethics of attaining child assent with the intent of making our own efforts more effective in both this project and in future research with other First Nations communities. Focus groups are inexpensive, data rich, and stimulate participants to further explore the issue (Fontana \& Frey, 1994). Focus groups are known for their effectiveness because they bring together individuals and groups attempting to understand differences in perspectives, factors that influence those perspectives, and innovative ways of proceeding in the future (Krueger \& Casey, 2009). The focus groups were clearly delineated as such and differentiated from team meetings. Seven research team members, representing both community and academic perspectives, participated in the initial two and a half hour focus group and a second 90 minute focus group held specifically on child assent

Following iterative readings of the focus group transcripts, the data was reduced and then analyzed thematically as is standard in qualitative analysis of focus groups (Krueger \& Casey, 2009). Issues of cross-cultural communication, salience, and intent are important and were actively considered in the analysis (Dreachslin, 1998). The trust that developed between team members over a three-year period was evident in the depth of discussion and willingness to explore alternate views. Preliminary interpretations of the data were checked through circulation of the transcript and, subsequently, the draft manuscript to research team members as is standard in CBPR research (Israel et al., 1998; Macaulay et al., 1999).

\section{Research Findings}

\section{“Why do I need to sign it?" Exploring the Child Assent Process}

The process of obtaining assent and the children's reactions were reviewed as an initial grounding to the discussion. While parent or guardian consent was carried out in the child's home, the program facilitator for the Nimi Icinohabi program, a community member and community-based research team member, asked the children to sign the informed assent forms during class time. She explained the research aspects of the program to the children including completion of pre and post questionnaires and a sharing circle for those who participated in the Nimi Icinohabi program. She clarified that all children in the intervention group would receive the program; however the signed assent was needed for completion of the questionnaires and participation in the sharing circle.

The cohorts of children involved in this research component of this project (grades three, four, seven, and eight) appeared puzzled by the request to sign assent. After explaining what was being asked of them, the facilitator recalled, "they had the opportunity to ask questions, being kids they didn't hesitate. They wanted to know, 'What's this about? Why do I have to sign 
my name? What's this for?'" The children were particularly interested in knowing whether their parents or guardians had signed a consent form. They were then shown the forms their parents/ guardians had signed; a reassuring move that the facilitator believed was important to increasing their comfort level with signing their assent.

In carrying out the assent process and in interpreting the children's reactions the facilitator spoke about relying on, "how growing up [I was taught]... my own teachings and things that were in lessons l've learned." One of these lessons was the significance of the kinship system in the community. Recalling the children's reactions, she considered the issue in light of her grandfather's concern that people were no longer using the proper kinship terminology. The children's reaction to being asked for assent was interpreted by the facilitator and other community-based team members as an indication of their understanding of the kinship system. Their reactions were taken as an encouraging sign that the community was making headway in their efforts to retain and revive culturally appropriate normative expectations of kin including the children's relationship with the facilitator. Thus from this perspective, the fact "that the kinship system still seems to be there" was interpreted as a good thing which needs to be respected in carrying out future research assent.

\section{Conflicting Paradigms of Protection}

Western academic norms, found in documents such as the TCPS-2 (Canadian Institute of Health Research et al., 2010), upon which Canadian REBs base their decisions, stress minimizing potential risks for children in an effort to avoid repeating past abuses. The activities involved in protection from risk that Western academic policies were intended to provide (i.e. autonomy, justice, and independence) were seen by community-based team members to be counter to this goal. In fact, risk accrued from the REB protections. From her perspective as a Nakota woman who has raised her own family, the facilitator explained that asking the kids for assent rather than relying on their parents or on overall community consent was considered unnecessary. Reflecting not only her own opinion but also her perceptions of fellow community member's views, she commented that, "if someone were to come to me and explain this research project and I signed that consent, I'm signing the consent for myself and my child."

Another issue presented was the role of dual relationships or consent bias. One of the university-based team members, to promote discussion of strategies for negotiation with REBs, voiced institutionally framed REB concerns regarding duality in research relationships when obtaining consent or assent. She noted that, "the ethics committee might say [that since] you know the people and you have a relationship with them, perhaps you are influencing their decision in some way to agree to participate, so.... you're actually introducing some bias into the consent." In response, one of the community-based researchers voiced her frustration regarding the lack of understanding regarding community relational ethics and the inappropriateness of this argument: "I am related to practically everybody here somehow. And if we are not related we make kinship [ties] somehow. So, you know, to use that argument, I don't think it will apply." In the context of this community and its history, obtaining parental/guardian consent and child assent was seen as best carried out by trusted community members who in most cases are also relatives. Additionally, in asking for child assent at the school, the facilitator was both a relation and teacher for the Nimi Icinohabi program. As part of the culturally adapted program, she was engaged in teaching the children proper protocol for asking for participation or help from others in an entirely different manner from the university assent protocol. In this case, the duality of roles is not a source of conflict in gathering child assent, but rather a means for increasing confidence 
in the safety of the research relationship, thus creating conditions appropriate for assent.

\section{Dilemmas Related to Rights-based Approaches to Child Assent}

As the discussion progressed, the universitybased researchers expressed their belief in the importance of additional training for institutionally based REB members on the unique challenges of child assent within a First Nations context. For instance, one university-based team member held that while the usual REB approaches to child assent, even for First Nations children, was appropriate in the context of standard medical research, a very different approach was needed in carrying out CBPR research. As she explained, "within a medical research context I believe a child has a right to decide what will or what will not go into their body, whereas in a social research context that decision is perhaps more appropriately decided collectively." At the same time, one of the other university-based team members believed that in either research context culturally-based assent approaches are required for First Nations children and families.

Assent as a form of children's rights was also discussed and differing perspectives shared. One university-based participant indicated that even if differing processes were used in this community or others like it, the need to ensure the child has the right to refuse participation remained essential. She pointed out that, "the child may have some reason why they don't want to participate, you're taking away that right to express themselves [if you don't use some form of individual child assent]." In response, another university-based researcher pointed out that for her what was more significant was that, "in carrying out forms of consent that are not culturally appropriate, particularly in a program like this one with an emphasis on cultural values ... if you put [the children] in a position to do something that is contrary to their cultural upbringing, you're imposing something upon them as opposed to removing a right." Finding a way to respect differing definitions of children's rights and how individual rights and/or collective rights are prioritized from within culture was seen as presenting particular challenges by focus group members from both university and First Nations contexts. It may be that these complex issues must be negotiated and assumptions examined before determining procedures case by case.

\section{Issues of Trust, Safety, Respect, and Ownership}

Issues of trust, safety, respect for community protocol, and research ownership were raised for discussion and problem solving by community. based researchers throughout the project, often in response to REB requirements. Communitybased researchers experienced the required consent procedures and paperwork burdensome but also, as disrespectful (Fletcher et al., 2010). For this and many First Nations communities, trust remains an issue when using written forms of agreement with Western institutions. As one of the community-based researchers put it, "consent is like negotiating with Western ideology....this is because this is not ours"(emphasis original). Another powerful dynamic raised is that, "over history our people signed with x's. So the fear of what you're signing is always going to be there." She reminded the non-First Nations universitybased team members that, "the country of Canada, your government, came in and made a decision on this country and so all you guys are following it ... but this isn't our way." Communitybased team members interpreted the children's hesitance to sign assent forms to mean that they have heard these stories and incorporated them in their attitudes towards signing an assent form individually in the school setting.

Maintaining cultural traditions and teaching the children cultural protocol as an important aspect of life skills development are goals of the Nimi Icinohabi project. Yet communitybased research team members indicated that Western institutional perceptions of children which emphasize individualism were seen as contributing to inappropriate and unhealthy 
forms of role reversal for children, parents, and relatives. Reaction to the request for child assent can be understood in that light. As one communitybased team member explained, based on traditional values and customs, "the family, or the community was the one that took care of the child - the community ... not only the parents but the community." Asking the community, children and families to do otherwise was seen as disrespectful of these values and roles.

\section{Protecting Contexts of Role Responsibility in Decision-making}

Decision-making about activities that could affect the whole community is understood as "not something for the young." To support this statement, two of the community-based team members recalled that a highly respected Elder (Paul Potts) recommended increasing the age from 21 to 25 fro participation on the First Nation Council. His teaching was that before this age young people can't "make decisions ... in the best interest of the community ... because they're like immature children that are making the decision for the community." In contrast, the communityteam members described Western institutions like schools, health care, child welfare services, and the REB as encouraging children to make choices they are not mature enough for or that are properly not theirs to make including, in this case, child assent. Concern was raised that this may put the children "in conflict with some of their kinship responsibilities" by encouraging them to challenge parents' and relatives' decisions." When this happens the child may be "in conflict with the community because the child was given the responsibility of the family."

Asking a child to make a decision that an adult should be making for them or that the community as a whole should make is giving the child adult responsibility before they are ready for it. A story that illustrates what can happen when these norms aren't respected was shared. In this case the child's guardian, the grandmother, allowed the child to do as he wished rather than to follow the recommendations of a team of community educators, health specialists, and other relatives. Today the child is grown up and in difficulty. As a result, "the community suffers from that child not being educated, that child being illiterate. That child is not really contributing to the community." When children are put in inappropriate roles like this, particularly by outside institutions, "you're allowing the child to be the parent." This can result in the kind of values and role loss that was understood by community team members as contributing to increased child welfare involvement, which then affects the family's kinship responsibility, respect, and wellbeing.

The point being made was that current child assent procedures, which stress individualism, are another example of a process that conflicts with community norms. To explain concern regarding this undermining effect further, a teaching from another Elder (Nancy Potts) was offered by one of the community-based team members: "You have to shape that child [in our culture] until he gets to a certain point. And then if you raise that child to become independent then they'll be able to go on its own." In contrast, the Elder described intervention by Western systems as, "making a point with laws [which stress independence and individuality]" and "through law [you] make somebody else [rather than the community] be responsible to raise that child" and as a consequence, "you're going to affect the family responsibility."

\section{Carrying Out Assent "in a Good Way"}

The final focus group question asked, "What kind of consent/assent process would allow us to work respectfully within the community and still meet REB expectations and can we find some way to satisfy both?" In response, communitybased team members recommended that, ideally, issues of parent/guardian consent and child assent be addressed in a "campout" setting open to all community members. In this "on the land" approach, the program and research activities could be discussed while also holding land-based 
cultural activities. By obtaining community and parental consent, along with child assent in a collective setting, you would begin the program with appropriate cultural protocol, roles, and build relationship with the project. Being on the land would also set the activity in a place of comfort, cultural safety, and spiritual integrity while reinforcing the value of the traditional Nakota life skills emphasized by the Nimi Icinohabi program. Other collective settings suggested for obtaining consent included holding a gathering or feast at the community school or in some other public centre.

This process, however, may not always be possible and some families may want more time to think about their choice in giving consent or to talk with Elders or other family members. Going out to family homes, not just for parental/guardian consent as we do now, but for a joint family consent process where at least one adult would sign as well as the child/ren involved would then be the best way to proceed. Acknowledging the difference from usual REB procedures, one of the community. based researchers argued, "the university, you know, doesn't want the student and parents to do it together... but ...that's not how we do it" (emphasis original). Carrying out consent/assent at home in a supportive and culturally congruent context was seen as "allowing the parent and the child to make that decision together."

While acknowledging that these processes can be time consuming, all team members agreed that obtaining child assent, either in a campout setting or at the child's home, must reflect community ownership and be based in community values. This is a very different process from that of Western practice which aims to ensure that children are free from undue influence from their parents or guardians and respect for the child's growing autonomy fostered. For the Alexis Nakota Sioux "no Ione person" makes decisions that might affect the community as a whole (Fletcher et al., 2010); children appear aware of this. Their response to signing assent suggests that they are uncomfortable in an individual spotlight, especially given that from their perspective the decision has already been made by their leaders, parents/guardians, and Elders. Rights based in Western values should not come at the expense of disturbing cultural values that have been retained and are being brought back to life by the community. Instead, one of the university-based team members suggested that, "if you could have that community and family ... consent you're going to respect the values and the beliefs of the community and you are going to meet the expectations of a Western academic ethics review board."

\section{Discussion}

Table 1 illustrates significant differences that exist between this First Nations community and Western values and approaches pertaining to the issue of child assent. The column on the left indicates priorities from the perspective of Western research ethicists and research ethics boards. The right hand column indicates priorities from the perspective of Elders and community researchers from the Alexis Nakota Sioux Nation. They reflect differing ethical frameworks that developed in particular socio-cultural contexts experienced over time. As part of this dynamic, the right side reflects not only Nakota norms but also response to the assertion of values from the left side.

The Western priorities and values listed, evolved in light of very real concerns regarding abuses in earlier research practice. Ensuring children's autonomous involvement in research is presented as not only good practice, but as a right (Powell \& Smith, 2009). Increasingly, it is argued that REBs should allow for children's consent rather than simple assent. However, in this community asking for child assent by children in isolation is seen as disrespectful of the collective nature of the community, the sociohistorical relationship of risk, the proper role of one's relations in decision-making and, further, as putting children at risk by placing them in a culturally unsafe position.

Areas of understanding that emerged in light of the literature review and the individuals' 
Table 1: Two perspectives of the ethics and values involved in child assent.

\begin{tabular}{|l|l|}
\hline \multicolumn{1}{|c|}{ Western Priorities } & \multicolumn{1}{c|}{ Alexis Nakota Sioux Nation Priorities } \\
\hline Individual autonomy/freedom. & Family and community responsibility. \\
\hline Ensuring child's independence. & Ensuring child's safety/cultural safety. \\
\hline Privacy and confidentiality are a priority. & $\begin{array}{l}\text { Individuals don't make decisions privately which } \\
\text { affect the community. }\end{array}$ \\
\hline $\begin{array}{l}\text { Individual assent free from possible influence of } \\
\text { parents. }\end{array}$ & $\begin{array}{l}\text { Collective responsibility to protect child from } \\
\text { within community/ family and for the children to } \\
\text { follow guidance of Elders. }\end{array}$ \\
\hline $\begin{array}{l}\text { Assessment of developmental competence to } \\
\text { make decisions. }\end{array}$ & $\begin{array}{l}\text { Protection from harm of being placed in } \\
\text { individual (alone) dilemma rather than safety of } \\
\text { community. }\end{array}$ \\
\hline $\begin{array}{l}\text { Advocacy for children's individual human rights } \\
\text { and issues of justice. }\end{array}$ & $\begin{array}{l}\text { Rights based in community self-government and } \\
\text { community self-determination in response to } \\
\text { injustice. }\end{array}$ \\
\hline $\begin{array}{l}\text { Assessment of harms and benefits from within } \\
\text { a dominant cultural norms and systems of } \\
\text { political and economic power. }\end{array}$ & $\begin{array}{l}\text { Assessment of harms and benefits from context } \\
\text { of history, marginalization and affects of } \\
\text { dominant culture on own culture. }\end{array}$ \\
\hline Avoid dual roles in research relationships & Find connections in all relationships \\
\hline $\begin{array}{l}\text { Respect and empower dignity of child as adult- } \\
\text { like, able to stand up for self. }\end{array}$ & $\begin{array}{l}\text { Protect cultural dignity by surrounding child in } \\
\text { protection of community. }\end{array}$ \\
\hline
\end{tabular}

experiences of this research project, as captured in this focus group, contrast with Western assumptions in the following ways:

1. The relative importance or degree of emphasis on parental consent versus child assent, along with differences in perceptions on who is most fit to decide in the case of children.

2. The role of making ethical decisions based on an appeal to the authority of codes, rights, and other legalistic mechanisms versus the need to make decisions based on the impacts on relationships with others, including family, clan, and community.

3. The need to obtain child assent away from the influence of family or others that might influence their decision versus the need to protect children while helping them learn their responsibilities to their family and community and to learn proper protocol for making decisions within this context.
4. The need to examine differing culturallycentered beliefs regarding who, how, and where decision making with/for children in research occurs, their developmental readiness, and the factors involved in decisions and how this effects concepts related to children's interests, child development, and avoidance of risk.

Thus, actions must be taken that ensure that individuals and communities, to benefit from research impact and outcomes, are not required to adhere to any procedures that undermine children as they learn values and responsibilities in cultural contexts. In this case they should not be asked to forgo community norms for their protection. Thus, child assent as conducted in this project was, in some ways, disrespectful of culturally based teachings regarding community collectivity and protocol and thus not likely to fulfill the intent of either community or institutional ethics as they relate to the protection or best interests of children. 
In this sense, we are obligated to reconsider the issue of non-malfeasance, or doing no harm. Is non-malfeasance, a concept embedded in a Western ethical perspective, undermining the traditional ethical norms of this community? The request for assent puts the child in a stressful situation, given community norms which stress that, "no lone person" makes decisions affecting the whole community (Fletcher et al., 2010). The Alexis Nakota Sioux children involved in this project likely sensed that this is not the proper way to make decisions; asking them to do so appeared to make them uneasy. The children also seemed perplexed by being asked to give written assent by a community member who they respect but who should know that "this isn't the way." This was demonstrated by the fact that many of the children asked a number of questions before signing. For example, in asking repeatedly whether their parents or guardians had already signed and why they needed to sign, the children appear to be asking whether their relatives, who usually speak on their behalf, approved and whether the program facilitator, as a member of the community, believed that the community thought this was okay. This also puts community-based researchers in a place of ethical conflict in that they are asking the children to sign something in a manner that is not culturally appropriate. Further, doing so presents a mixed message given that this substance abuse prevention program, Nimi Icinohabi, involves teaching children appropriate culturally-based ethical protocols. Finally, research should not replicate or re-inscribe harm done in the past, one aspect of which is ensuring respect for the collective nature of consent in this community.

\section{Conclusion}

To protect children in research, academic researchers and REBs have developed a Western rights-based process based on the child as an individual. To protect children, within the traditional Nakota Sioux culture, they are surrounded in context by family, clan, Elders, and community leaders and protected from value conflicts with the larger society. Dialogues involving children and child assent for research participation are bound up in narratives of interaction with Western systems along with traditional beliefs about proper ways to raise children within collective dignity.

Western narratives are about the dignity of the child as an individual with rights while protecting them by preventing the research abuses of the past. Ethical frameworks involving children ask researchers to balance vulnerability with any injustice occurring as a result of their omission and to consider the likelihood of any pain, anxiety, or injury while considering the nature and degree of any harmful impact on child participants. Other factors commonly addressed are decision making readiness, avoiding duality in roles, and careful consideration of who should or should not participate in decisions regarding children's involvement in research. All of these issues are affected by worldview and cultural frames.

We believe that extrinsic vulnerability occurs in asking First Nations children to engage in activities that reduce or minimize cultural protection. From this background, practices imposed by REBs are, in some ways, seen as analogous to imposed government practices and deserve re-consideration in light of this historical and ongoing context. Consideration for the research must take place within socio-historical, relational, and cultural contexts. If not, it may not be in the child, family, or nation's best interest to participate in the research.

We found significant differences in what is seen as appropriate ethical conduct, including the appropriate degree of focus on protocol, relationship and responsibility for others, and the process and/or practices involved. Thus, current child assent processes may contribute to undermining community and cultural maintenance. At the least they may make all those involved uncomfortable with the process and the message. Adherence to Western ethical protocol over community protocol leads to the 
replication and reinforcement of colonial systems and can do harm. In a project such as this, where use of teaching materials that are culturally adapted to reflect community values is a priority, this conflict puts all those involved in a double ethical conflict. These choices cannot be based in Western principles of ethical utilitarianism but must occur from within culturally-based ethical principles and protocol for asking for assistance.

Some questions regarding the need to obtain child assent at all were raised given that consent for the children's participation was already received from the community through a BCR, Elder's through their participation in and support of the project, and parents/guardians though the approved REB informed consent process. Nevertheless, two recommendations for conducting child assent were developed. They both include carrying out child assent in the context of culture, family, and safety and are aimed at equalizing differing traditions of ethics and protocol while affirming the traditional roles of Elders and families in protecting children.

Although the research literature is beginning to address the issue of obtaining child assent in projects in First Nations communities, this issue needs further exploration. Limitations to this study include a small, single case sample. However, it is believed that similar and even more complicated issues would occur in projects with larger sample sizes or across multiple cases. As well, variation exists within and between communities. The issues addressed here raise important points that may be applicable in other contexts; however, protocols, views, and best practices need to be considered community by community. Nonetheless, this is an important issue that warrants additional research on appropriate processes of child assent for research in First Nations communities. Additional REB responsiveness to these processes is also needed. Reforming policy, as it pertains to parent consent and child assent, may be one way to begin to reinstate First Nations people's control over their communal lives and self determination with regard to their present and future.

\section{References}

American Academy of Pediatrics. (2004). Ethical considerations in research with socially identifiable populations. Pediatrics, 113, 148-151.

Ball, J. (2005). 'Nothing about us without us': Restorative research partnerships involving Indigenous children and communities in Canada. In A. Farrell (Ed.), Exploring ethical research with children (pp. 81-96). Berkshire, UK: Open University Press/McGraw Hill Education.

Ball, J., \& Janyst, P. (2008). Enacting research ethics in partnerships with Indigenous communities in Canada: "Do it in a good way". Journal of Empirical Research on Human Research Ethics, 3(2), 33-51.

Baydala, L.T., Sewlal, B., Rasmussen, C., Alexis, K, Fletcher, F., Letendre, L., ... Kootenay, B. (2009). A culturally adapted drug and alcohol abuse prevention program for Aboriginal children and youth. Progress in Community Health Partnerships, 3, 37.46.

Baylis, F., Downie, J., \& Kenny, N. (1998). Children in decision-making in health research. Health Law Review, 8(2), 3-9.

Beauchamp, T.L. \& Childress, J.F. (2001). Principles of biomedical research. New York: Oxford University Press.

Botvin, G.J., \& Griffin, K.W. (2004). Life Skills Training: Empirical findings and future directions. Journal of Primary Prevention, 25, 211-232.

Botvin, G.J., Griffin, K.W., Paul, E., \& Macaulay, A.P. (2003). Preventing tobacco and alcohol use among elementary school students through Life Skills Training. Journal of Child and Adolescent Substance Abuse, 12, 1-17.

Brant Castellano, M. (2004). Ethics of Aboriginal research. Journal of Aboriginal Health, 1, 98-114.

Broome, M. E. (1999). Consent (assent) in research with pediatric patients. Seminars in Oncology Nursing, 15, 96-103.

Burns, J. (2003). Research in children. Critical Care Medicine, 31, S131-S136.

Canadian Institute of Health Research. (2007). CIHR Guidelines for Health Research Involving Aboriginal Research. Ottawa, ON: Government of Canada. Retrieved from http://www.cihr-irsc. gc.ca/e/29134.html. 
Canadian Institutes of Health Research; Natural Sciences and Engineering Research Council of Canada; Social Sciences and Humanities Research Council of Canada. (2010). Tri-council policy statement: Ethical conduct for research involving humans (2nd Ed.) (TCPS-2). Retreived from http:// www.ethics.gc.ca/pdf/eng/tcps2/TCPS_2_FINAL.

Canadian Institutes of Health Research; Natural Sciences and Engineering Research Council of Canada; Social Sciences and Humanities Research Council of Canada. (1998). Tri-council policy statement: Ethical conduct for research involving humans. Retrieved from http://www.pre.ethics. gc.ca/eng/policy-politique/tcps-eptc/

Castledon, H., Garvin, T., \& Huu-ay-aht First Nation. (2008). Modifying photovoice for community-based participatory Indigenous research. Social Science and Medicine, 66, 1393-1405.

Dreachslin, J.L. (1998). Conducting effective focus groups in the context of diversity: Theoretical underpinnings and practical implications. Qualitative Health Research, 8, 813-820.

Esbensen, F., Deschenes, E.P., Vogel, R.E., West, J., Arboit, K., \& Harris, L. (1996). Active parental consent in school-based research. Evaluation Review, 20, 737-753.

Esbensen, F., Melde, C., Taylor, T.J., \& Petersen, D. (2008). Active parental consent in school-based research? How much is enough and how do we get it? Evaluation Review, 32, 335-362.

Fisher, C.B., Hoagwood, K., Boyce, C., Duster, T., Frank, D.A., Grisso, T., ... Zayas, L.H. (2002). Research ethics for mental health science involving ethnic minority children and youths. American Psychologist, 57, 1024-1040.

Fletcher, F., Baydala,L., Letendre, L., Worrell, S., Letendre, S., Schramm, T., \& Ruttan, L., (2010). "No lone person:" The ethics consent process as an ethical dilemma in carrying out community based participatory research with a First Nations community. Manuscript submitted for publication.

Fontana, A., \& Frey, J. H. (1994). Interviewing: The art of science. In N.K. Denzin \& Y.S. Lincoln (Eds.), Handbook of qualitative research, (2nd ed.), (pp. 361-376). Thousand Oaks, CA: Sage.
Hammack, F. (1997). Ethical issues in teacher research. The Teachers College Record, 99, 247.65.

Hill, M. (2005). Ethical considerations in researching children's experience. In S. Greene \& D. Hogan (Eds.), Researching children's experiences: Approaches and methods (pp. 61-86). London: Sage Publications.

Holaday, B., Gonzales, O., \& Mills, D. (2007). Assent of school-age bilingual children. Western Journal of Nursing Research, 29, 466.485.

Holkup, P.A., Rodehorst, T.K., Willhelm, S.L., Kunts, S.W., Weinart, C., Stepans, M.B.F., ... Hill, W.G. (2009). Negotiating three worlds: Academia, nursing science, and tribal communities. Journal of Transcultural Nursing, 20, 164-175.

Hurley, J.C., \& Underwood, M.K. (2002). Children's understanding of their research rights before and after debriefing: Informed assent, confidentiality, and stopping participation. Child Development, 73, 132-143.

Israel, B., Schultz, A., Parker, E., \& Becker, A. (1998). A review of community-based research: Assessing partnership approaches to improve public health. Annual Review of Public Health, 19, 173-194.

Krueger, R.A., \& Casey, M.A. (2009). Focus Groups: A Practical Guide for Applied Research. (4th ed.). Thousand Oaks, CA: Sage.

Lederer, S.E., \& Grodin, M.A. (1994). Historical overview: Pediatric experimentation. In M. A. Grodin \& L. A. Glanz (Eds.), Children as research subjects: Science, ethics, and law (pp. 103-130). New York: Oxford University Press.

Macaulay A. C., Commanda L., Freeman, W., Gibson, N., McCabe, M., Robbins, C., ... Twohig, P. for the North American Primary Care Research Group. (1999). Participatory research maximises community and lay involvement. British Medical Journal, 319, 774-8.

Marshall, P. A. (2006). Informed consent in international health research. Journal of Empirical Research on Human Research Ethics, 1, 25-42.

Meaux, J.B., \& Bell, P. L. (2001). Balancing recruitment and protection: Children as research subjects. Issues in Comprehensive Pediatric Nursing, 24, 241.251. 
First Peoples Child \& Family Review, Volume 6, Number 1, 2011

Morrow, V., \& Richards, M. (1996). The ethics of social research with children: An overview. Children \& Society, 10, 90-105.

Nelson-Marten, P., \& Rich, B. (1999). Informed consent in clinical practice and research. Seminars in Oncology Nursing, 15, 81-88.

Nolen, A.L., \& Putten, J.V. (2007). Action research principles in education: Addressing gaps in ethical principles and practices. Educational Researcher, 36, 401-407.

Panagiotopoulos, C., Rozmus, J., Gagnon, R.E., \& Macnab, A. J. (2007). Diabetes screening of children in a remote First Nations community on the west coast of Canada: Challenges and solutions. Rural and Remote Health, 7, 771.

Powell, M.A., \& Smith, A.B. (2009). Children's participation rights in research. Childhood, 16, 124-142.

Ruttan, L. (2004). Exploring ethical principles in the context of research relationships. Pimatisiwin: A Journal of Aboriginal and Indigenous Community Health, 2, 11-28.

Shore, N., Wong, K., Seifer, S. D., Grignon, J., \& Gamble, V. N. (2008). Introduction to special issue: Advancing the ethics of community-based participatory research. Ethics, 3, 1-4.

Schnarch, B. (2004). Ownership, control, access, and possession (OCAP) or self-determination applied to research. Journal of Aboriginal Health, 1, 80-95.

Smith, L.T. (1999). Decolonizing Methodologies: Research and Indigenous Peoples. Dunedin, NZ: Zed Books.

Weithorn, L., \& Scherer, D. (1994). Children's involvement in research participation decisions: Psychological considerations. In M. Grodin \& L. Glanz, (Eds.), Children as research subjects: Science, ethics, and law (pp. 133-179). New York: Oxford University Press. 